\title{
Simulasi Monitoring Ketinggian Air Danau dan Kontrol Pompa Air Menggunakan Modul Arduino di Bandara Internasional Juanda Surabaya
}

\author{
Oleh: \\ Hartono \\ Wempy Brilliansya
}

\author{
Politeknik Penerbangan Surabaya \\ Jl Jemur Andayani I/73 Wonocolo Surabaya 60236 \\ Telp.(031)841087, Fax (031)8490005 \\ Email: hartono.subawi @yahoo.co.id
}

\begin{abstract}
Overflow of lakes can be occured in Juanda International Airport at rainy season because the pump is too late to flow water into the river. To solve this problem, the technician must come to the location to check the water level and operates the pump. The operation of the pumps by technicians is not effective because there is no automatic control and Human Machine Interface system in PC. whilethe distance from the technician room to the Pump House is far enough and costed time to reach the place.

Due to the situation, the writer designed an automatic control water pump and monitoring water level of lake and river with arduino module. Ultrasonic sensor HC-SRO4 is used to determine the water level and control the pumps. Current sensor ACS-712 detects the current from the pumps. After the water level and current for the pump is determined the results will be displayed in PC using visual basic as human main interface
\end{abstract}

Keywords: Lake, River, submersible pump, Ultrasonic sensor HC-SR04, current sensor ACS712, Arduino Uno and Visual Basic.

\section{PENDAHULUAN}

Bandar Udara Internasional Juanda adalah salah satu bandara yang dikelola oleh PT. Angkasa Pura I (Persero) merupakan Badan Usaha Milik Negara(BUMN) yang bergerak dalam bidang pengusahaan jasa kebandarudaraan. Seperti halnya bandara-bandara komersil lainnya, Bandara Internasional Juanda juga mempunyai tugas pokok yaitu melaksanakan pemberian jasa pelayanan operasi keselamatan lalu lintas udara, disamping itu juga memberikan rasa nyaman bagi para penumpang baik yang akan berangkat maupun yang baru datang.

Salah satu fasilitas untuk keselamatan penerbangan diantaranya yaitu adanya danau. Danau menurut pengertian umum adalah cekungan di permukaan bumi yang cukup luas dan digenangi oleh air, kemudian air yang melimpah tersebut dimanfaatkan untuk berbagai keperluan lainnya pada saat musim kemarau.

Di Bandara Internasional Juanda Surabaya terdapat dua danau. Danau yang pertama berada di ujung runway 28 dan danau yang ke dua berada di ujung runway 10 dengan ukuran kurang lebih $1690 \mathrm{~m}^{3}$. Air yang di tampung di dalam waduk tidak hanya dari hujan, melainkan berasal dari air limbah kotoran kotoran dari terminal yang sudah diolah untuk menghilangkan bakteri dan bau. Fungsi utama di bangunnya waduk ini yaitu untuk mengatasi agar runway tidak pecah-pecah pada saat musim kemarau, yang berakibat fatal apabila runway dalam keadaan pecah-pecah. Dari setiap danau ini terdapat pompa yang digunakan untuk membuang air ke sungai maupun laut pada saat melebihi batas akibat hujan ataupun banyaknya air pembuangan kotoran yang telah diolah. Terdapat 6 pompa pada tiap danau dengan kapasitas masing masing 10 PK yang digunakan untuk memompa air ke sungai. 
Apabila power dari PLN padam, maka Generator set yang terdapat di PH akan memback-up. Pompa yang digunakan merupakan pompa submersible atau disebut juga pompa benam.

Pada musim penghujan, di Bandara Internasional Juanda pernah terjadi meluapnya danau dan telatnya pompa untuk membuang air ke sungai yang mengakibatkan air sungai juga ikut meluap bahkan sampai menggenangi rumah warga sekitar bandara. Untuk mengatasi hal tersebut, seorang teknisi harus menuju ke lokasi untuk melihat level danau dan mengoperasikan pompa. Dalam pengoperasian pompa oleh teknisi tersebut dipandang kurang efisien karena belum adanya kontrol otomatis dan sistem HMI pada PC.Jarak ruang teknisi ke Pump House yang terletak di dekat danau pun juga cukup jauh yaitu sekitar $2 \mathrm{~km}$.

Seiring dengan perkembangan teknologi dan kemajuan pengetahuan bidang elektronika, dimungkinkan untuk merancang peralatan kontrol otomatis untuk pengoperasian pompa dan monitoring ketinggian air danau dengan menggunakan modul Arduino. Sehingga penulis ingin mengaplikasikan modul Arduino untuk pengoperasian sistem pompa pembuangan air danau pada ujung runway di Bandara Internasioal Juanda Surabaya dan dijadikan topik sebuah penelitian yang berjudul "SIMULASI MONITORING KETINGGIAN AIR DANAU DAN KONTROL POMPA AIR MENGGUNAKAN MODUL ARDUINO DI BANDARA INTERNASIONAL JUANDA SURABAYA". Kondisi Saat Ini

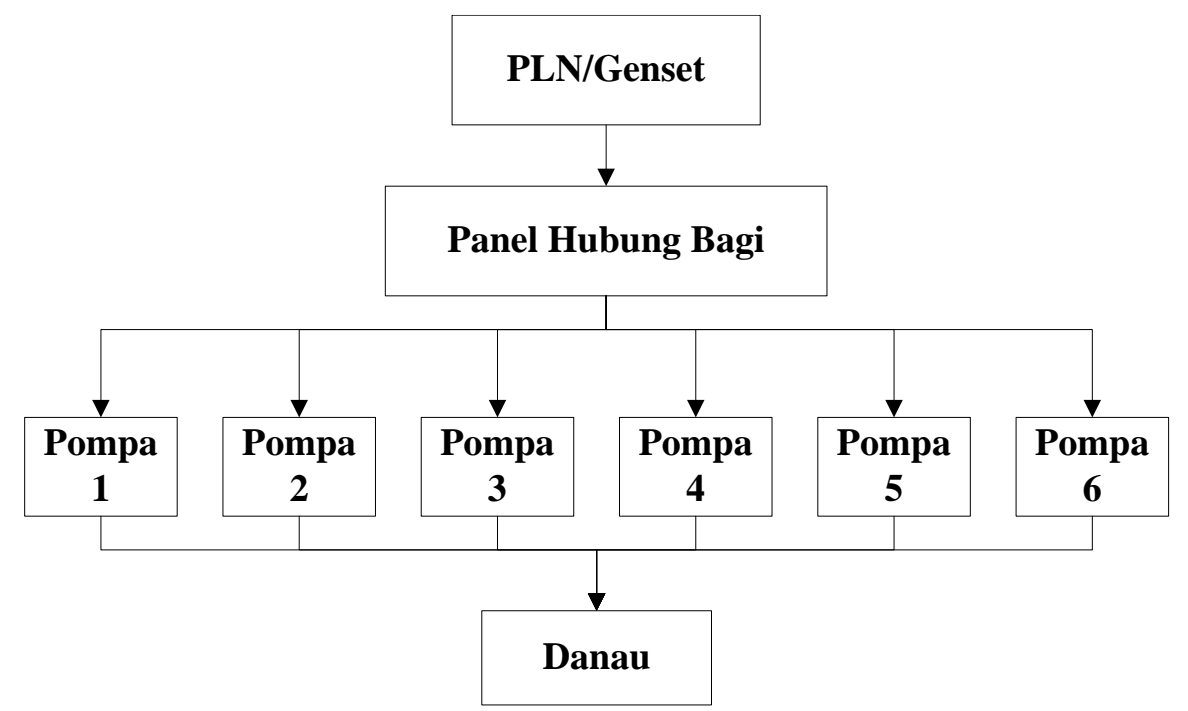

Gambar 1. Blok Diagram Kondisi Saat Ini

Sistem pompa pembuangan air yang ada saat ini hanya dapat dioperasikan secara manual yaitu dengan mengoperasikan switch sebagai pengendalinya. Pada musim penghujan, di Bandara Internasional Juanda pernah terjadi meluapnya danau dan telatnya pompa untuk membuang air ke sungai yang mengakibatkan air sungai juga ikut meluap bahkan sampai menggenangi rumah warga sekitar bandara. Untuk mengatasi hal tersebut, seorang teknisi harus menuju ke lokasi untuk mengoperasikan pompa. Pengoperasian secara otomatis belum dapat dilakukan karena belum ada piranti yang mendukung untuk pengoperasian. 


\section{Kondisi yang diinginkan}

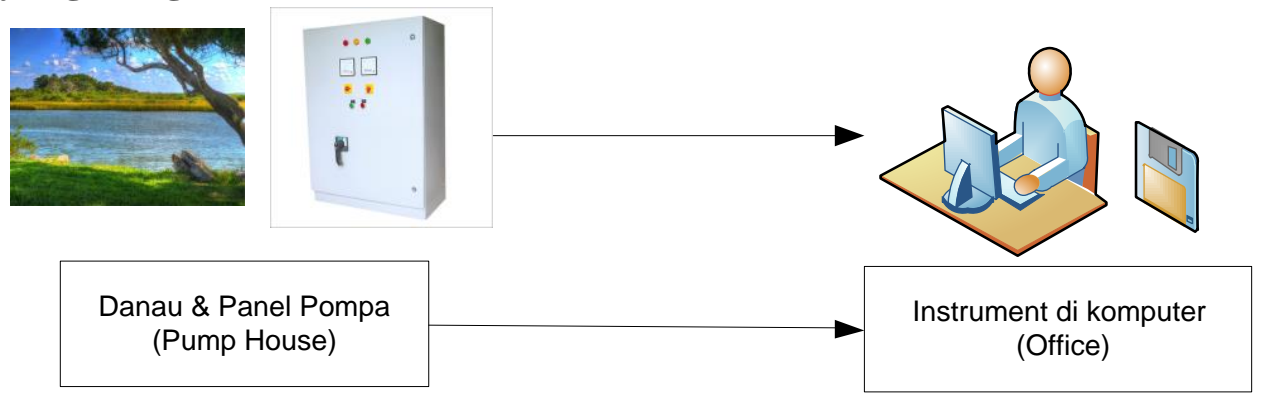

Gambar 2. Sistem Monitoring dan Kontrol Pompa Air Danau Yang Diinginkan.

Dengan di tambahkan alat ini dimaksud agar dapat mengurangi beban kerja teknisi. Sehingga sistem pompa pembuangan air yang semula hanya bisa dioperasikan secara lokal, dengan di tambahkan alat pada rancangan ini sistem pompa pembuangan air tersebut dapat dioperasikan secara otomatis dan pompa dapat termonitoring apabila terjadi kelebihan beban dan tidak menghisap air, pada pompa dapat juga direset dari kantor sehingga teknisi tidak perlu ke rumah pompa tersebut. Alat ini selain dapat digunakan sebagai penyimpanan data sehingga teknisi tidak perlu datang ke lokasi untuk mengetahui keadaan level air. Hasil dari monitoring sistem pompa pembuangan air danau di Bandara Internasional Juanda Surabaya akan ditampilkan pada komputer dengan Visual Basic.

\section{METODOLOGI PENELITIAN}

\section{Konsep Rancangan}

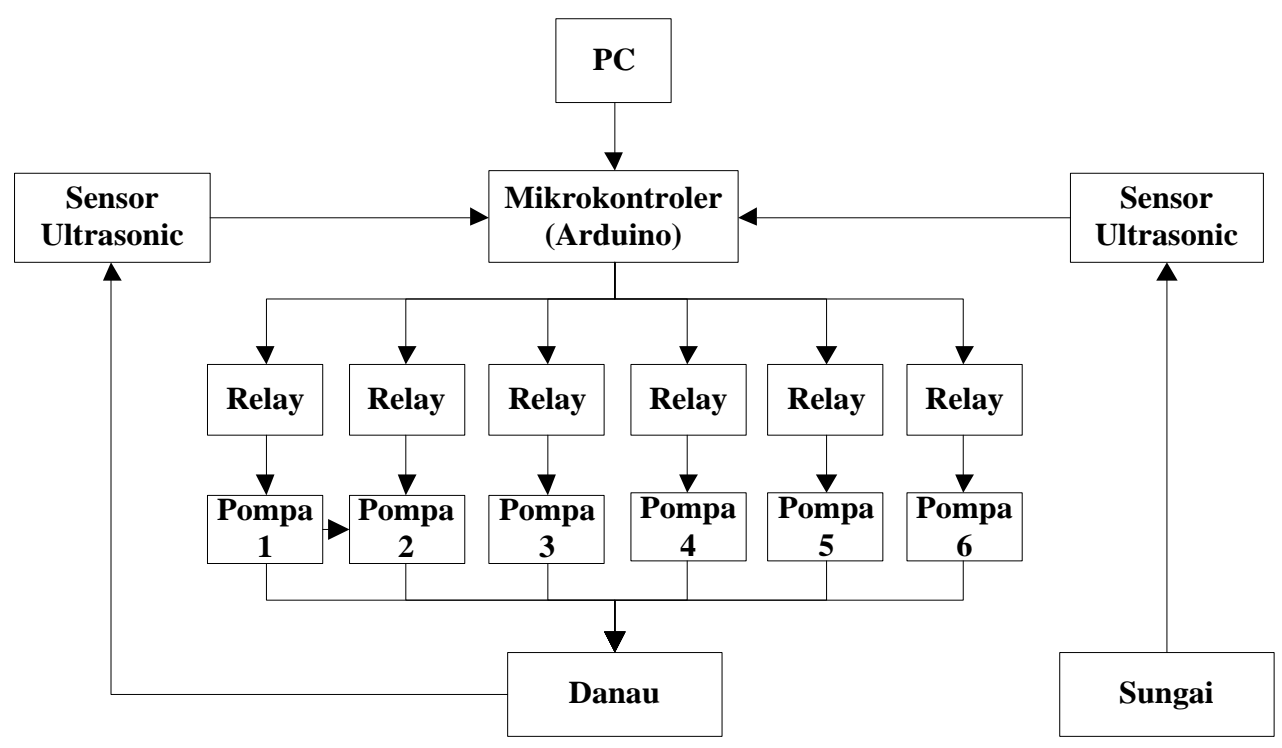

Gambar 3. Blok Diagram Perancangan Alat

Pada gambar blok diagram rancangan alat di atas, peneliti akan menggunakan dua sensor ultrasonic yang akan dipasang pada danau dan sungai. Hal ini bertujuan untuk memonitoring level ketinggian air danau dan sungai. Sensor ultrasonic pada sungai digunakan untuk indikator pompa diperbolehkan menyala atau tidak, sedangkan sensor ultrasonic pada danau digunakan sebagai indikator berapa banyak pompa yang akan menyala. Ketika level sungai mencapai $\leq 2 \mathrm{~m}$, maka secara otomatis pompa akan menyala. Namun, apabila level sungai $\geq 2 \mathrm{~m}$, maka otomatis pompa tidak akan menyala, meskipun level sungai 
lebih dari $3 \mathrm{~m}$. Apabila sungai mencapai $\geq 2 \mathrm{~m}$ dan dibiarkan pompa menyala, maka dikhawatirkan sungai akan meluap dan menggenangi rumah warga di sekitar bandara. Ketika level danau mencapai $3 \mathrm{~m}$ dan tidak $\leq 3,2 \mathrm{~m}$ maka otomatis pompa 1 akan menyala. Ketika level danau mencapai tidak $\leq 3,4 \mathrm{~m}$ maka pompa 1 dan 2 otomatis akan menyala. Ketika level danau mencapai tidak $\leq 3,6 \mathrm{~m}$ maka otomatis pompa 1,2, dan 3 akan menyala. Ketika level danau mencapai tidak $\leq 3,8 \mathrm{~m}$ maka otomatis pompa 1,2,3, dan 4 akan menyala. Ketika level danau mencapai tidak $\leq 4 \mathrm{~m}$ maka otomatis pompa 1,2,3,4, dan 5 akan menyala dan apabila $>$ $4 \mathrm{~m}$ maka seluruh pompa akan otomatis menyala.

\section{HASIL PENELITIAN}

\section{Pengujian dan Analisa}

Pengujian rancangan ini dilakukan dengan empat percobaan sesuai dengan level ketinggian air danau (Hd) dan level ketinggian air sungai (Hs) :

1. $8 \mathrm{~cm}<\mathrm{Hd} \leq 16 \mathrm{~cm}$ dan $(\mathrm{Hs}) \leq 15 \mathrm{~cm}$ (Ketinggian air danau lebih dari $8 \mathrm{~cm}$, kurang dari $16 \mathrm{~cm}$ dan air sungai kurang dari $15 \mathrm{~cm}$ ).

2. $16 \mathrm{~cm}<\mathrm{Hd} \leq 24 \mathrm{~cm}$ dan $(\mathrm{Hs}) \leq 15 \mathrm{~cm}$ (Ketinggian air danau lebih dari $16 \mathrm{~cm}$, kurang dari $24 \mathrm{~cm}$ dan air sungai kurang dari $15 \mathrm{~cm}$ ).

3. (Hd) $>24 \mathrm{~cm}$ dan $(\mathrm{Hs}) \leq 15 \mathrm{~cm}$ (Ketinggian air danau lebih dari $24 \mathrm{~cm}$ dan air sungai kurang dari $15 \mathrm{~cm}$ ).

4. (Hs) $>15 \mathrm{~cm}$ (Ketinggian air sungai lebih dari $15 \mathrm{~cm})$.

\section{Pengujian Pertama}

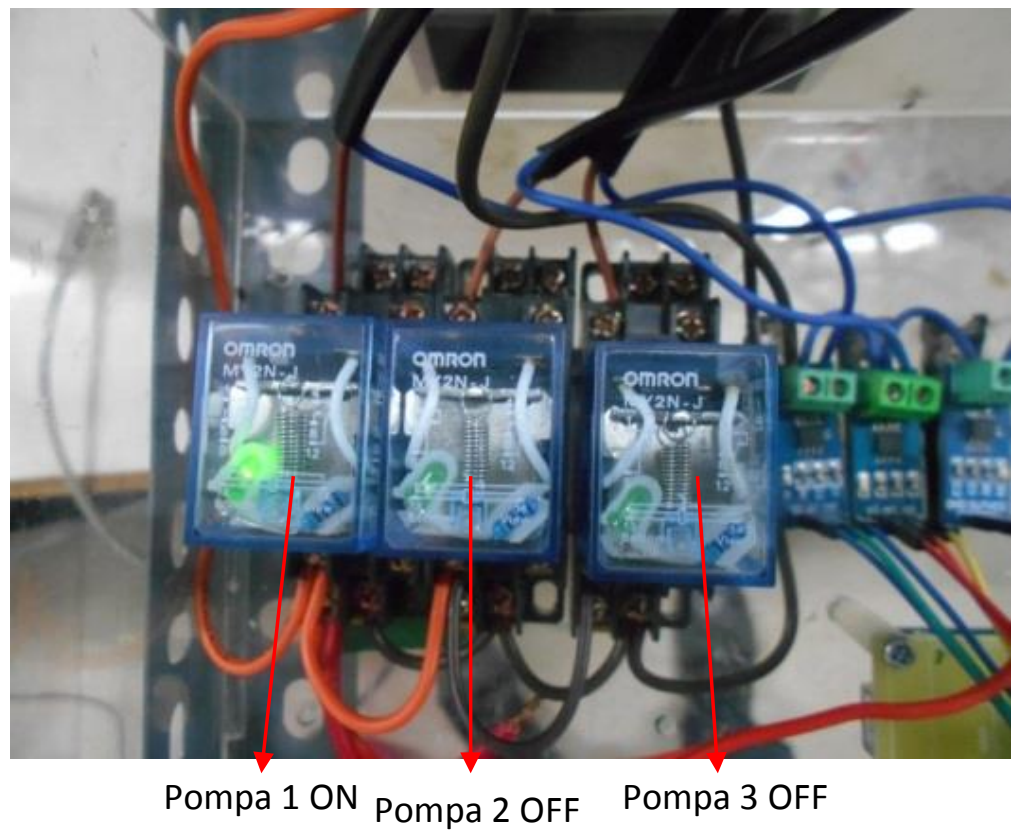

Gambar 4. Relay pompa pada pengujian pertama 
Pada pengujian pertama yaitu ketika $8 \mathrm{~cm}<\mathrm{Hd} \leq 16 \mathrm{~cm}$ dan $(\mathrm{Hs}) \leq 15 \mathrm{~cm}$. Dalam pengujian ini menggunakan level danau $10,12,14 \mathrm{~cm}$ dan didapat hasil sebagai berikut:

Tabel 1. Hasil Pengujian Pertama

\begin{tabular}{|c|c|c|c|}
\hline $\begin{array}{c}\text { Level Danau } \\
(\mathrm{cm})\end{array}$ & Pompa 1 & Pompa 2 & Pompa 3 \\
\hline 10 & ON & OFF & OFF \\
\hline 12 & ON & OFF & OFF \\
\hline 14 & ON & OFF & OFF \\
\hline
\end{tabular}

Berdasarkan data hasil pengujian pada tabel 1, bahwa didapat hasil sesuai dengan keinginan yaitu ketika $8 \mathrm{~cm}<\mathrm{Hd} \leq 16 \mathrm{~cm}$ dan $(\mathrm{Hs}) \leq 15 \mathrm{~cm}$ pompa 1 menyala dan pompa 2,3 tidak menyala.

\section{Pengujian Kedua}

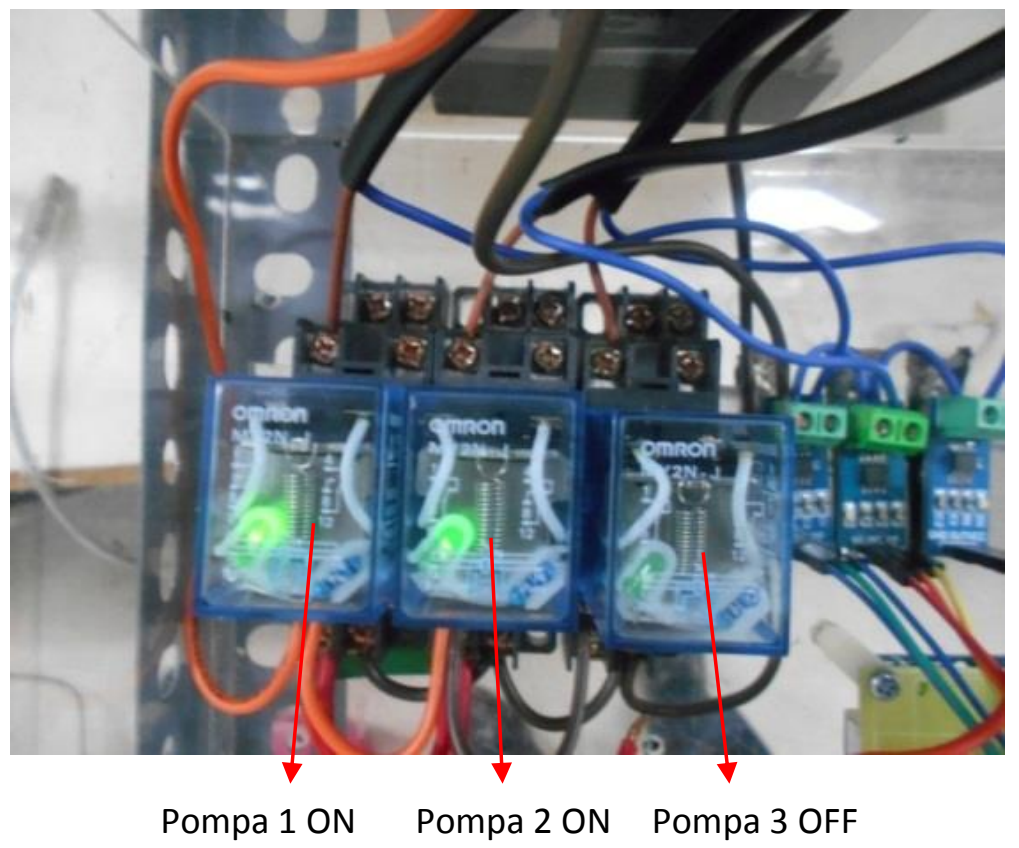

Gambar 5. Relay pompa pada pengujian kedua

Pada pengujian kedua yaitu ketika $16 \mathrm{~cm}<\mathrm{Hd} \leq 24 \mathrm{~cm}$ dan $(\mathrm{Hs}) \leq 15 \mathrm{~cm}$. Dalam pengujian ini menggunakan level danau 18,20, $22 \mathrm{~cm}$ dan didapat hasil sebagai berikut:

Tabel 2. Hasil Pengujian Kedua

\begin{tabular}{|c|c|c|c|}
\hline $\begin{array}{c}\text { Level Danau } \\
(\mathrm{cm})\end{array}$ & Pompa 1 & Pompa 2 & Pompa 3 \\
\hline 18 & ON & ON & OFF \\
\hline 20 & ON & ON & OFF \\
\hline 22 & ON & ON & OFF \\
\hline
\end{tabular}


Berdasarkan data hasil pengujian pada tabel 2, bahwa didapat hasil sesuai dengan keinginan yaitu ketika $16 \mathrm{~cm}<\mathrm{Hd} \leq 24 \mathrm{~cm}$ dan $(\mathrm{Hs}) \leq 15 \mathrm{~cm}$ pompa 1,2 menyala dan pompa 3 tidak menyala.

\section{Pengujian Ketiga}

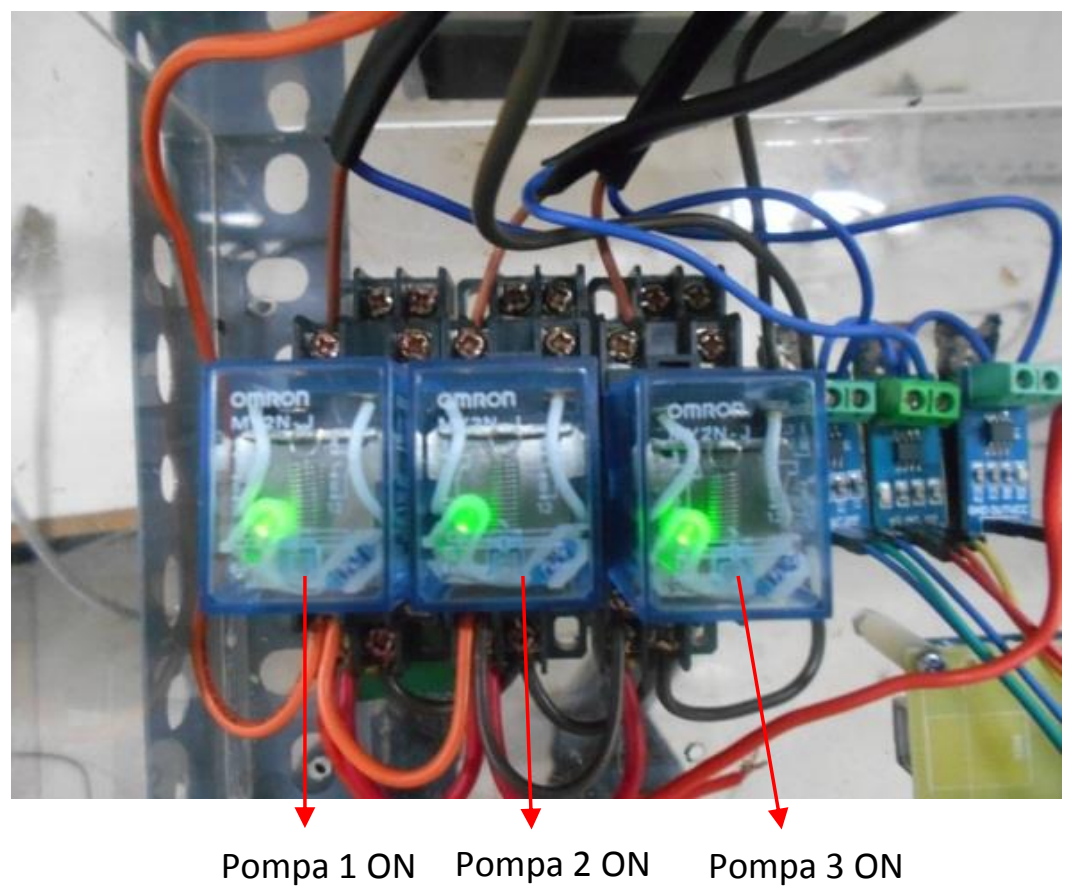

Gambar 6. Relay pompa pada pengujian ketiga

Pada pengujian kedua yaitu ketika $(\mathrm{Hd})>24 \mathrm{~cm}$ dan $(\mathrm{Hs}) \leq 15 \mathrm{~cm}$. Dalam pengujian ini menggunakan level danau 26, 28, $30 \mathrm{~cm}$ dan didapat hasil sebagai berikut:

Tabel 3. Hasil pengujian ketiga

\begin{tabular}{|c|c|c|c|}
\hline $\begin{array}{c}\text { Level Danau } \\
(\mathrm{cm})\end{array}$ & Pompa 1 & Pompa 2 & Pompa 3 \\
\hline 26 & ON & ON & ON \\
\hline 28 & ON & ON & ON \\
\hline 30 & ON & ON & ON \\
\hline
\end{tabular}

Berdasarkan data hasil pengujian pada tabel 3, bahwa didapat hasil sesuai dengan keinginan yaitu ketika $(\mathrm{Hd})>24 \mathrm{~cm}$ dan $(\mathrm{Hs}) \leq 15 \mathrm{~cm}$ pompa 1,2 dan 3 menyala. 


\section{Pengujian keempat}

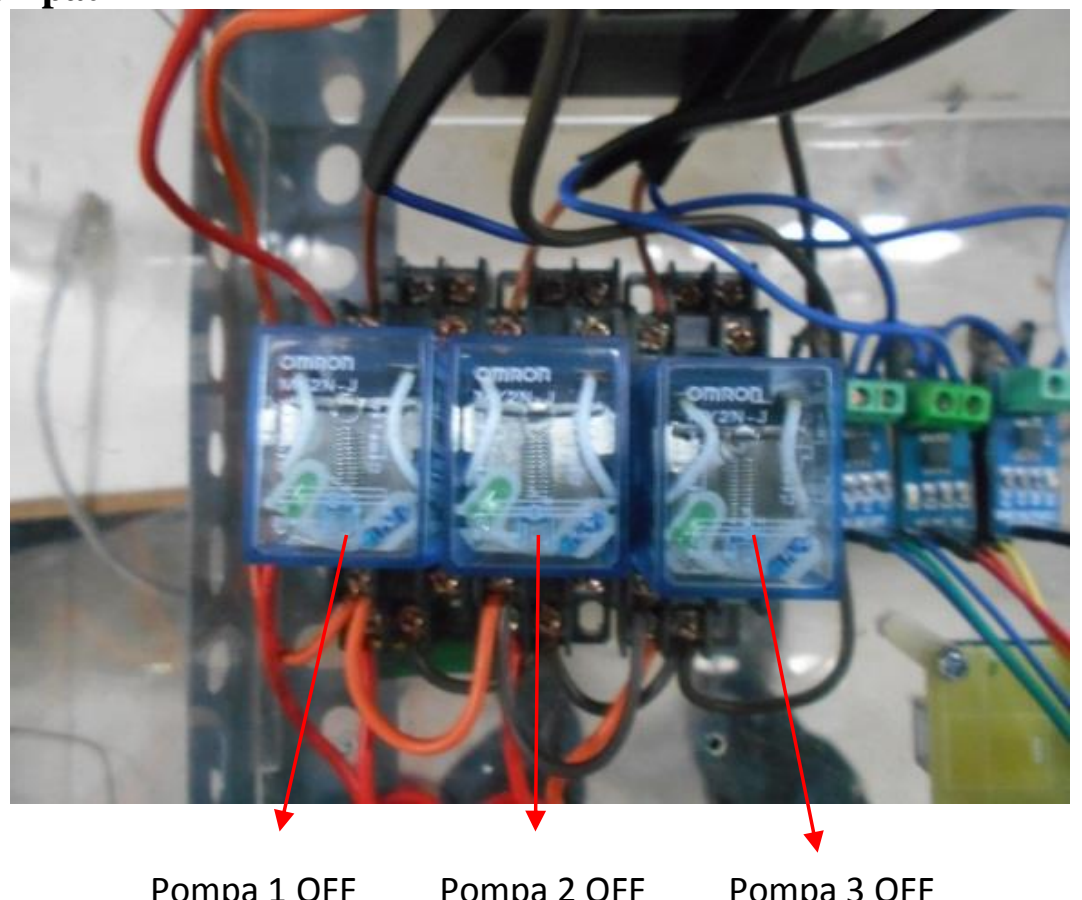

Gambar 7. Relay pompa pada pengujian keempat

Pada pengujian pertama yaitu ketika $(\mathrm{Hs})>15 \mathrm{~cm}$ dan didapat hasil sebagai berikut:

Tabel 4. Hasil pengujian keempat

\begin{tabular}{|c|c|c|c|}
\hline $\begin{array}{c}\text { Level Danau } \\
(\mathrm{cm})\end{array}$ & Pompa 1 & Pompa 2 & Pompa 3 \\
\hline 26 & OFF & OFF & OFF \\
\hline 28 & OFF & OFF & OFF \\
\hline 30 & OFF & OFF & OFF \\
\hline
\end{tabular}

Berdasarkan data hasil pengujian pada tabel 4, bahwa didapat hasil sesuai dengan keinginan yaitu ketika $(\mathrm{Hs})>15 \mathrm{~cm}$ pompa 1,2 dan 3 tidak menyala.

\section{KESIMPULAN}

Berdasarkan dari hasil percobaan-percobaan di atas dapat diambil kesimpulan antara lain:

1. Dengan adanya rancangan sistem kontrol yang baru maka dapat merubah sistem kontrol manual menjadi sistem kontrol otomatis.

2. Dengan memanfaatkan perangkat mikrokontroller arduino dan teknik pengiriman data yang tepat sehingga level air danau dan kondisi pompa dapat termonitoring dari jarak jauh melalui PC.

\section{DAFTAR PUSTAKA}

Akademi Teknik dan Keselamatan Penerbangan Surabaya, 2013, Modul Mesin Listrik II. Surabaya : ATKP Surabaya.

Akademi Teknik dan Keselamatan Penerbangan Surabaya, 2013, Modul Desain Sistem Kontrol. Surabaya : ATKP Surabaya. 
Sianipar, Bonar S.H. 2011. Modul Institut Sepuluh Nopember : Visual Basic 10. Surabaya : Institut Sepuluh Nopember.

Willa, Lukas. 2007. Teknik Digital, Mikroprosesor dan Mikrokomputer. Bandung : Informatika. 